akademik Tonko Maroević

Hrvatska akademija znanosti i umjetnosti

\section{Bijeli dvori u sjenama sutona Književni luk sudbine
dubrovačkih ljetnikovaca}

kazališnog i filozofsko-znanstvenog izraza autora iz iste sredine (okvirno: od Držića do Gundulića, preko Gučetića, Nalješkovića ili Getaldića), da pokriva i prve manifestacije glazbene kulture i visoke uljuđenosti, te da traje i dotrajava sve do pada Republike, nije čudno i neobično što uz ambijente izvangradskih vlasteoskih dvoraca i uz atmosferu ladanja povezujemo i znatan broj kreativnih dometa dubrovačkih pisaca, mislilaca, skladatelja i izumitelja. Uostalom, postoje nemala svjedočanstva o prožetosti stvaralaštva $s$ duhom povlaštenih prostora samoće i kontemplacije. $\mathrm{Uz}$ zrelu arhitekturu, istančanu hortikulturu i nemimoilaznu agrikulturu svoje je mjesto našla i široko shvaćena kultura ladanja, koja je uz dobrodošle zemaljske plodove urodila i ne manje poželjnim manifestacijama ljudske osjetljivosti i težnje fiksiranja tragova vlastitoga prolaska dragim i bogomdanim prostorima življenja, odmaranja i djelovanja.

Zahvaljujući inicijativi profesora Preloga, nekolicina nas je još u studentskim danima i u ranim profesionalnim angažmanima bila u prilici upoznati brojne dubrovačke ljetnikovce na mnogim lokalitetima. Proučavali smo ih i opisivali, surađivali na njihovoj spomeničkoj inventarizaciji, odnosno sakupljali građu (arhitektonske snimke, fotografije i inu dokumentaciju) za njihovu zaštitu i eventualnu obnovu. Osjećali smo izrazitom povlasticom to što smo mogli upoznati okružje u Rijeci dubrovačkoj, gdje su se okupljali muzikalni Sorkočevići, boraviti u paviljonu Gučetićeva ljetnikovca u Trstenom, gdje se vodio glasoviti »Dijalog o ljepoti i i onaj o ljubavi, suočiti se s ruševnim zidovima zgrade u Kobašu, u kojoj su Betondići prevodili Ovidija, vidjeti 
kulu Cvijeta Zlatarića u Pijavičinom, gdje se hvali ljepotom pejzaža, ili posjetiti ostatke prelijepog ladanjskog sklopa biskupa Beccadellija na Šipanu, u kojemu je on čak očekivao dolazak svojega prijatelja Michelangela (pa je i njegov portret, uz ostale humanističke likove i asocijacije, dao naslikati na zidovima). Samim usputnim nabrajanjem nekoliko karakterističnih primjera ulazimo u meritum fascinacije fenomenom dubrovačkih ljetnikovaca, evociramo ambijente koji su osim svojim fizičkim izgledom i uronjenošću u krajolik privlačili i svojom kulturno-povijesnom dimenzijom, zračili nam i značili pozitivne tekovine »dugog trajanja«.

Da se ne zavaravamo, i spomenute ljetnikovce i mnoge druge - u Konavlima, u Župi, u Rožatu, u Cavtatu, u Stonu, na Lopudu, na Lapadu, na Šipanu, na Pelješcu - upoznavali smo u stanju gotovo potpune zapuštenosti. Uz iznimku Trstena i Sorkočevićeva ljetnikovca u Gružu, svi su bili oronuli, često sasvim napušteni, mnogi već i srušeni. Možda je među nama bilo i osoba romantičarske osjetljivosti i »ruinističke» orijentacije, morbidnoga ukusa za »sunt lacrimae rerum«, ali ni mi ostali nismo mogli izbjeći sjetu, tugu i melankoliju, pa čak i stid zbog odnosa naše sredine i našega vremena prema takvim spomenicima. Uostalom, profesor Prelog nas je - takoreći od samoga početka - podsjećao kako je to "baština bez baštinika «, te je glasnim upozoravanjem na zanemarene vrijednosti graditeljstva i pripadne im stvaralačko-povijesne dimenzije pokušao probuditi svijest šire javnosti i mjerodavnih institucija o nužnosti njihove konzervacije, rekonstrukcije i restitucije u odgovarajuće funkcije.

Između desetak tada mladih povjesničara umjetnosti, koji su u ranim šezdesetim godinama evidentirali i istraživali dubrovačke ljetnikovce vrlo brzo se svojom motivacijom izdvojila Nada Grujić. Nećemo kazati da je bila vođena većim iluzijama ili izravnim perspektivama obnove, ali se ponajmanje mirila sa stanjem stvari, makar s rezervama nije sasvim rezignirala. Patetično bi bilo kazati da se osjetila prozvanom kao »baštinica«, no istina je da je od studentskih dana do danas najveći dio energije uložila $u$ analizu i interpretaciju dubrovačkih ljetnikovaca, a njih je prirodno uklopila u općenito proučavanje dubrovačkog graditeljstva i gradogradnje. Čitavom serijom studija, s nekoliko ukoričenih knjiga, zdušno se posvetila pojavi i kulturi dubrovačkog ladanja. I dok je ona bilježila i tumačila stanje na terenu, dok se ona zalagala za povremene prikladne intervencije, dubrovački ljetnikovci doista nisu ostali sasvim bez baštini$\mathrm{ka}$, a svoju svijest o vrijednostima uspjela je prenijeti barem jednoj izabranoj manjini, dok je svoje spoznaje i procjene sačuvala u pisanom obliku da makar sljedećim naraštajima posluže kao memento i kao orijentir za eventualno sretnije ponašanje s dragocjenim nasljeđem.

Višedesetljetno bavljenje Nade Grujić posvećeno obradi i proučavanju istaknutih i manje razglašenih spomenika graditeljske i uljudbene prakse u dubrovačkoj regiji zaslužuje svaku pohvalu. Gotovo da nema zakutka na prostoru nekadašnje Republike u koji ona nije stupila, da bi na licu mjesta provjerila znane podatke, dopunila empirijski spoznaje i - konačno no ne manje važno - doživjela građevine u svojemu ambijentu i, nažalost, pretežno u situaciji neizbježne degradacije ili čak uništenja. Strast terenskog rada potom je povezala sa skrupuloznošću analize dostupnih arhivalija, te s komparativnom metodom traženja stilskih i tipoloških paralela.

U ranijim fazama učestalih terenskih istraživanja sa zadovoljstvom sam bio svjedokom njezinih zanosa otkrićima novih objekata i razočaranja zatečenim stanjem spomenika, no ona nikad nije klonula duhom, nego je ustrajno nastavljala radom. I kad bi se sada trebalo odužiti Nadi za uloženi trud i postignute rezultate, nažalost ne umijem pridodati niti kamičak u mozaik povijesnoumjetničkog situiranja i vrednovanja fenomena renesansno-barokne izgradnje dubrovačkog ladanja. A umjesto da sam literariziram ili opjevavam atmosferu vlasteoskih dvorova, pokušat ću naznačiti sukus književnih odjeka ili ulančanih lirskih reakcija što ih, već stoljećima, izazivlju ljetnikovci davnih gospara.

Naravno, nemimoilazne činjenice i interpretacije u tom smislu ponudio je Cvito Fisković u dvjema komplementarnim studijama: "Kultura dubrovačkog ladanja (1966.) i »Dubrovački ljetnikovci i književnost« (1979.). Poslužit ću se dobrim dijelom upravo njegovim radovima, ali ću ekstrahirati samo neke komponente, naročito u namjeri da ocrtam evidentnu amplitudu uspona i pada, radosti stvaranja i sjete zamiranja, vedre intonacije otkrivene ljepote i nujnog tona nužne dekadanse. Odabrani naslovni binom rječito govori: formulacija »Bijeli dvori« - iz pera Meda Pucića - odnosi se na razdoblje ponosnog urastanja u krajolik, a sintagma "u sjenama sutona« - preuzeta od Luja Vojnovića - adekvatno tumači raspoloženja nas kasnopridošlih na slavlje ladanjskog življenja.

Dok su dvorovi bili bijeli - da parafraziramo jednu drugu glasovitu naslovnicu - u njima su se zbivale sjajne svečanosti i vesela druženja. O tomu nažalost nemamo svjedočanstva iz prve ruke, recimo situiranje neke komedije, farse, ili ovećeg teksta u prostore ljetnikovca. Iznimka su Gučetićevi i Nalješkovićevi (talijanski pisani) predgovori njihovim filozofskim spisima, gdje hvale svoje ladanje kao mjesta sabranosti i razmjene ideja s kolegama. Svojevrsnu iznimku pruža nam i najautoritativniji od svih, Marin Držić, kad u svojim stihovima evocira svojega prezimenjaka, Džoru, kao pjesnika koji se nadahnjuje ambijentom Rijeke dubrovačke:

Sad jedan mlad djetić s tim vilam pri vodi stare kuće Držić svu mladost provodi, koga su tej vile od bistra hladenca dostojna učinile od lovorna venca...

Hladenac jes jedan tuj blizu kraj gore, izvire mora van, a teče u more: 
Rieka se taj zove hladenac medeni, vrhu svih ki slove u gori zeleni.

Ali i sam Marin priznaje kako ne odolijeva istom ambijentu, te u pjesmi Sabu Nikolinovu Gunduliću potvrđuje vlastiti boravak uz nadahnjujuću Rijeku:

poslušaj s ljubavi Držića, pri vodi, u slavnoj dubravi ki s vilam dan vodi.

Neće stoga biti pretjerano pomisliti kako je svoje pastorale zamišljao kao projekcije u idilične znane mu prostore ladanja, iako ih je, razumije se, dopunio ironičnim ili čak grotesknim elementima. Premda su i »Tirena« i »Grižula» uprizoreni u gradskom okružju, njihovo je ishodište izvan zidina, njihov je - i duhovni i zbiljski - izvor svakako u blizini Omble.

Koliko se boravak na ladanju smatrao inspirativnim najbolje potvrđuje Dinko Ranjina, ponosni graditelj - danas srušenoga - ljetnikovca u Vrućici, pokraj Trpnja na Pelješcu, kada baš tamo poziva u goste, očevidno zamukloga, pjesnika Maroja Mažibradića:

Dođi k meni malo sad...

na ovi dvor mili moj sazidan na vodi, pod kojim drijeva broj svakojakih dohodi, daj na glas Serena, ka uza nj dan trate, jeda t' se ljuvena spjevanja povrate.

U svojem odgovoru stariji pjevidrug izražava nevoljkost prihvaćanja ljubeznog poziva, tvrdeći kako ga životne muke i žalosti priječe da se vrati pjevanju. Ali u uvodnom tekstu poslanice, dijelom kalkirajući formulaciju Ranjinina poziva, pokazuje poštivanje ladanjskog ambijenta, afirmira poticajnost življenja izvan gradske buke i dnevnih preokupacija, jer je i sam proveo mnogo vremena na svojim imanjima $u$ Konavlima i na Pelješcu. Marojevo uzvraćanje Dinku vrlo je dugačko, a dio što se odnosi na stimuliranje nadahnuća u prirodnom krajoliku glasi:

Zoveš me na dvor tvoj, sazidan na vodi, gdi plavi velik broj svakojakih dohodi, i morske gdi vile pjesni ti spijevaju, i kê te tač mîle, da živeš u raju; a sve toj er tvoja vrijednos hoće i žudi, da se pamet moja na pjesni probudi. Ako t' su boljezni, zov' me da se bolim, a nemoj na pjesni, velmi te sad molim. Zač spijevat nije mi moć, kako to odzgar rih, u meni nije moć, neg sam pun tuga svih.

Pjesnički dijalog poslanicama u stihovima svojevrsna je konstanta dubrovačke, a i općenito južnohrvatske, kulture, no s obzirom na našu temu posebno je zanimljiv slučaj pjesničke komunikacije u sljedećemu naraštaju, gdje je jedan od sugovornika upravo sin Maroja Mažibradića, Oracio. I on je naslijedio očev ljetnikovac s imanjem u Konavlima, gdje rado boravi i otkud se javlja prijateljima u gradu:

Njeki dan sjedeći prid brijestom u hladu, te ovo misleći stanih se u gradu, dođe mi na pamet velika tva ljubav, stah mislit: ja ću t’ rit, jesi li živ i zdrav, kako mož živiti bez drazijeh prijatelja? Tamo u toj zabiti n'je li te od nas želja? Što li te otiri iz ovijeh širina, da tamo meu miri prži te toplina? Što li se ne dvigneš za ljubav daj staru, na mjesec doć daj dvaš k nami, gospodaru?

Dakle, osim naglašavanja prijateljskog druženja na ladanju, argumentacija poziva je i nesnosna omara unutar gradskih zidova. Nakon retoričkih evokacija mogućih razloga izostanka adresata iz prostora slobodne zabave i razonode, te odmora u prirodi (ili ga je u gradu zadržala poslovna potreba, želja za zaradom ili je u nekoj ljubavnoj vezi) slijedi ponovljen poziv s imenovanjem konkretnog toponima (Uskoplje, selo u Konavlima) i nabrajanjem ženskih osoba, koje ga tobože željno iščekuju:

Želi te ovamo Uskoplje, krivalja i druga neg tamo čas ti se pripravlja: pjesni se pjevaju u zdravlje u tvoje, i u kolo igraju sve ove gospoje: Miona, Jerina, pod tvoj brijes dohode, i Mara, Šeina, ter kola izvode, i tebe skočaju želeć te dan i noć, i sveđ pogledaju kad im ćeš prije doć.

Ali možda najznačajniji primjer pjesničkog dopisivanja pruža nam obraćanje Oracija Mažibradića Plavkoviću, datirano 1623. godinom. Ono je, koliko znademo, jednostrano, što i nije sasvim čudno $s$ obzirom da se skromni i relativno siromašni građanin, kakav je Oracio Mažibradić, obraća uglednom vlastelinu, konkretno Đivu Gunduliću. Naime, Plavković je izmišljeno, novoskovano, poetično ime nastalo pohrvaćivanjem talijanizma gondola u dubrovački pojam plav (sinonim za drijevo ili brod), a naš ga pjesnik koristi upravo da izbjegne stalešku pukotinu između vlastite pučkosti i adresatova plemstva. U pjesničkoj, fikcionalnoj dimenziji komunikacija je, međutim, opravdana. Uostalom, nije li već i njegov otac Maroje, obraćajući se vlastelinu Ranjini, morao zauzeti stav poniznosti, čak vidljive nelagode zbog nejednakosti.

Oracijevo javljanje Plavkoviću motivirano je velikim poštovanjem, ali evidentno i željom za zaštitom ili pomoći u potrebi. Eventualna poetska solidarnost razabire se iz činjenice što je Gundulić bio spreman skromnijem kolegi pokazati (ili pročitati u širem društvu) neke svoje stihove, 
koji su Mažibradića - kako bar kaže - toliko oduševili i zanijeli da nije mogao odoljeti a da ne reagira pjesmom odanosti. Ono što nam je posebno zanimljivo je činjenica da Oracio evocira susret u dvoru na vodi, to jest $\mathrm{u}$ - davno srušenome - ljetnikovcu obitelji Gundulić u Rijeci dubrovačkoj, nekad smještenome upravo u zaleđu monumentalnoga zdanja obitelji Sorkočević. Nudeći se na službu uglednijemu, bogatijemu i društveno bolje pozicioniranom (pa i četvrt stoljeća mlađemu) autoru, Mažibradić junior tumači razloge svoje fascinacije i odanosti:

Rijet će razum tvoj bogati:
od kad ova služba ishodi?
Odgovaram: kad na vodi
u tebe se bi nam stati;
i kadno mi slatkijeh pjesni
množ ukaza milost tvoja,
od onada duša moja
sveđ za tobom gine i bjesni.

Zatim hvali Gundulića kao ljuvenog i duhovnog pjesnika, da bi ubrzo prešao na slavljenje obiteljske mu loze "prisvijetle krvi«s sbrojnim knezovima, a i s aktualnom moći u sudstvu i vlasti. $U$ daljnjem slijedu vrlo dugačke pjesme, od gotovo dvije stotine stihova, Oracio odjednom napušta svoj laskavi ton i prelazi na tužaljku o vlastitoj bijedi, napuštenosti i tragičnom obiteljskom stanju, očekujući valjda barem neku pomoć i društvenu podršku. Očigledno je neprirodna mezalijansa oholog vlastelina i siromašnog pučanina, pa je dodir na pjesničkom polju, susret u prostorima mašte, razonode ili opuštanja od svakodnevice jedina moguća kompenzacija za uskratu u zbilji. Mažibradić junior stoga bježi u svijet idile, ali je i tamo povlašteno mjesto već osigurano za moćnijega, uglednijega, glasovitijega. Mažibradićeva pohvala Đivu Gunduliću doživljava se danas i kao apologija življenja na ladanju i odavanja hedonističko-kreativnim poticajima u takvom ambijentu:

\section{U dubravam meu pastiri među skupim slijepih vila, gdje god bude družba mila, gdi se uzigra, poje i sviri, pripijevat će tvoje ime u glas visok do nebesa sloveć slavu tvoga uresa, da svud slovi nada svime.}

U ovom sasvim kratkom pregledu lirskih odjeka na boravak u ljetnikovcima zamijetili smo prevlast naglašavanja momenta na vodi. Doista, pjesnička je perspektiva povlastila atmosferu uzvodnih ili uzmorskih zdanja, kićenih dvorova što se odražavaju na blistavoj valovitoj površini tekućeg elementa i do kojih se prilazi lijepim i skladnim brodovljem. Uz vodu se, uostalom, okupljaju nimfe i vile, najade i nerejide, pa je mitska dimenzija okružja bila također više no poticajna. To se, najbolje razabire iz Gučetićeva talijanskog predgovora »Dijalogu o ljepoti«, u kojemu se - boraveći u Trstenom - Cvijeta Zuzorić obraća autorovoj supruzi: »jubezna moja Gundulice, molim vas, sjednimo u sjeni vrbe, tik do vode, koja kao da želi razgovarati s nama. Nije ni čudo - odgovori joj Marija - jer će možda njene nimfe, videći vas tako lijepu i slušajući vaš ugodni govor, smatrati da ste iz njihova jata i zaželjet će da ste s njima ... « Pohvala smještaju kraj mora i vode razvidna je i iz Nalješkovićeva predgovora spisu »Dijalog o sferama svijeta (pisanom također talijanski), gdje stoji - a odnosi se na ljetnikovac u Župi Dubrovačkoj: »Okrenem li pak oči k jugu, vidim široko more po kojem često plovi, vesla ili jedri punim jedrima neka lađa. Pogledam li konačno prema sjeveru, vidim brdo iskićeno tu i tamo vinogradima i bistrim vodama koje snažno izviru i razlijevaju se u potoke.«

Renesansno-baroknu navadu ljetovanja izvan grada, bijega od omare i gužve u slobodnu prirodu, održavao je još i u poodmaklom 19. stoljeću Pijerko Bunić, potomak značajne plemićke obitelji, koji se 1836. godine ovako dijeli od djedovskoga ljetnikovca u Rijeci dubrovačkoj:
Zbogom gore i dubrave,
Žive vode, ribe i tice,
Zbogom l'jepe djevojčice,
Ostaviću već vas ja,
Približa se crna zima,
Treba 'e meni bježat veće,
A kad dođe premaljeće
Iz nova ću k vama doć.

Ali ovaj, konkretno privremeni, rastanak možemo simbolično uzeti i kao definitivni rastanak vlasnika s imanjem, kao epilog navedenoj praksi korištenja ladanja. Vlastela uskoro pretežno izumiru ili se povlače iz javnog života, sredina je sve siromašnija i sve udaljenija od svake raskoši i ugode, a dvorci iljetnikovci bivaju ili napušteni ili prepušteni funkcijama skromnog stanovanja, ako ne i potpunom urušavanju. Dostojni nasljednik vlasteoskoga roda, pjesnik Medo Pucić u svojoj poetskoj slici Gruža (a u spjevu »Cvijeta«), elegično evocira skladne građevine:
Na obijem obalama stoje
Ponosite palače gospodske,
Bijeli dvori, ograde starinske,
Zupčastijem zidom zatvorene.

da bi u ponešto drugačijem kontekstu evidentirao i njihovu tragičnu sudbinu:

Izgorješe gospodske palače.

To se odnosilo na epizodu napoleonskih ratova kad su Rusi i Crnogorci, 1806. godine, spremajući se na sukob s 
Francuzima, poharali dubrovačku okolicu, spalivši čitava sela i mnoge pojedinačne zgrade i ljetnikovce, a pritom su stradali i obližnji dvorci u Gružu. Opustjeli i pomalo sablasni ambijent Gruža romantičarskim je očima gledao pjesnik Antun Paše Kazali, prepoznavajući karakterističan detalj:

I bieli se od prošasti

Kakav holi dvor.

Dakle, u razdoblje nakon Republike dubrovački ljetnikovci ulaze kao sjetna baština, kao »bijeli dvori«, kojima se prošlost diči i koje potomci spominju s nostalgijom kao mjesta visoke kulture i stvaralačkog napona idealiziranih predaka. Ivan August Kaznačić, u svojem tekstu »Izlet na Omblu«, pisanom talijanski, ovako opisuje okoliš Rijeke dubrovačke: "Obale su okružene visokim vijencem brda, što prelazeći postupno u blaže padine mijenjaju suhu ogoljelost svojih vrhova u bujnu vegetaciju obronaka, pokrivenih gustim maslinicima, između kojih se bijele lijepe grupe poljskih kućica, dok se uzduž obala dižu elegantni samotni dvorci, nekoć omiljeni ljetnikovci dubrovačkih vlasteoskih obitelji. U posljednjim je stoljećima bilo pomodno da drevna aristokracija oponaša običaje venecijanskog plemstva: Obale Omble bile su mjesto ljetnih užitaka poput onih na Brenti.« Josip Bersa u »Dubrovačkim slikama i prilikama« također posvećuje odgovarajuću pažnju fenomenu ladanja:

"Priroda, koja zaodijeva dubrovačku okolinu, ne mlazne u oči i u dušu silom raskoši i veličanstvenosti, već je mirna, blaga, skoro u se povučena, koja te obraduje i smiruje, miluje i krijepi. U toj sugestivnoj sredini počeše još zarana Dubrovčani graditi svoje dvorce za ljetni boravak. 'Kad su Muze - pjevao je Resti - po padu Carigrada pobjegle na obale Tibera, Arna i Brente, dolazile su i u naše krajeve, da poigraju na pristojnim igalima Župe ili da se okupaju u mirnim vodama Rijeke.' Guste šume lovorike i bistra vrela oni naseliše nimfama i pastirima; ali u zahlađu tih šuma i pri romonu tih vrutaka stvoriše i ona djela, sa kojih se proslavi i njihov zavičaj i cijela stara Hrvatska. Ljetnikovac je za Dubrovčanina mjesto zgodno za plemenitu dokolicu; tu je pjesma najmiliji odmor, tu je učenje dužnost i razgovor. Kuća za trajno stanovanje i dvorac za ljetno plandovanje malo se među sobom razlikuju, naročito u blizini grada, gdje se ravnomjerni gradski život i običaji nastavljaju; ta grad je malen, pa se mora širiti preko svoga kamenog pasa. Zato u predgrađima pravih villa nema..."

Na samome izmaku 19. stoljeća dubrovačke je ljetnikovce rado posjećivao povjesničar i literat Lujo Vojnović, općepoznati laudator temporis acti. Duboko impregniran doživljajem nekadašnje slave on obilazi istaknute lokalitete, a u duhu se druži s njihovim nekadašnjim vlasnicima i posjetiocima. Svoje »Dubrovačke elegije«, prvi put tiskane 1898. godine, posvetio je dobrim dijelom upravo hodočašćima na izvore ljepote i užitka, te registrira njihovo jadno stanje i osjeća gubitak funkcije koja je dvorce i činila bijelima. Primjerice, Sorkočevićev ljetnikovac u Gružu on vidi u kišnoj atmosferi i svjetlosti studenoga, pa nije čudno da tvrdi kako "gospodska zgrada jedri u sjenama sutona«. Pjesma u prozi »Novembar « ima podnaslov »u Pucić-Sorkočevićevu Dvorcu«, a započinje: »Niz pocrljenu odrinu lijeva dažd i na taraci polako hara korčulanske stubove«, da bi na koncu doživljaj zaokružilo prizivanje duhova prošlosti: "Samo vjetar kad i kad prođe kroz prorijeđene odrine i poviše glava odocnjelih carevića, a na vratima nemirna loza zazvoni zvonce, da navijesti tajanstvene, davne prolaznike.« $U$ drugoj pjesmi, »Humske vode« Lujo Vojnović opisuje brodarenje što također dovodi do nekadašnjega ljetnikovca:»I dopotezasmo se tromo do Sorgova dvorca. Čempresi sve jedan do drugoga, visoki, tmasti, prodirahu nebo kao crna falanga đinova, fantastične kule od baršuna, usudni svjedoci naše propasti. Sve pusto, sve nijemo."

Posjeta Gučetićevu dvorcu u Trstenom nadahnula je gospara Luja na pjesmu naslovljenu "Statuit, rexit, luget", što je natpis koji obrubljuje grb vlasničke obitelji, a znači "Zasnova, vladaše, žali«. Naravno, najbujniji i najljepši park, i do danas relativno sačuvan, potaknuo je zanosni epitaf epohi kad se zasnivalo i vladalo (ideji renesanse): »Druže se raznolike biljke kćeri Istoka i blijedih zapadnijeh strana. Putovi se gube puni mirisa i hlada. Svuda je veliki mir. Tritonima su polomljene trube, a Vergilijev sjen ne obilazi više oko isplavljenih Egloga. / / Bistre vode pjevajući slaze... / / I rascavćeni lovor priča sadovima ljubica kako su Epidaurski uskoci imali u tvrdome osvajačkome srcu sne velikijeh Gospara, potrebu božanske dokolice... Ne bučite. Prođite mirno, grančicom u ruci, kroz perivoj. Veliki Pan ovdje spava."

A pjesma "Sunt lacrymae« (što je navod glasovitoga Vergilijeva stiha, sa značenjem da i stvari žale, oplakuju nekadašnje bivanje) posvećena je preminuću i pogrebnoj svečanosti neke drage ženske osobe, koja »ostavi svoje dvore u sjeni Gospe i vlasteoske odaje na gruškijem vodama, ne dokončavši nikad svoj san, ne utaživši nikad žeđu slobode i ljubavi, nikada«. I mlađi Vojnović, Lujo, ne može nikako odijeliti osobne i društvene projekcije, elegiju ljuvenoga predznaka povezuje s povijesnom čežnjom o slobodi. Zato i njegova lirska kantilena nalazi svoje utočište »Na Mihajlu «, a njegov pogled na ambijent bitno je osjenjen prolaznošću: »I sad pristavlja tužnu žensku nezasićenu svoju priču čempresima Mihajla koji nose sve jače, sve teže breme bolova... Duge sjene padoše jedna po jedna na tragični grob.«

A Vojnović senior, Ivo, ponajmanje je mogao ostati ravnodušan na govor stvari i prostora, na svjedočanstva velike prošlosti i kreativnih dometa najdražega mu, zavičajnog ambijenta. Dubrovački su ljetnikovci pozornica dviju iznimno značajnih drama: drame »Na taraci«, trećega dijela blistave »Dubrovačke trilogije», i teksta »Prolog nenapisane drame«. Drugonavedena se samo u cjelini zbiva u ambijentu 
Skočibuhina renesansnog dvorca kraj Tri crkve, ali ga ne opisuje niti se na njega motivski referira (osim u smislu tragova sjajne prošlosti, koja magnetski privlači i svjetske pustolove i mondene filmske tvorce).»Na taraci«, međutim, povlašteno je gledalište na gruški prostor i povijesnu patinu koja sve više blijedi (ili, bolje kazano, tamni, s obzirom na to da se scena otvara u svjetlosti sutona). Uvodni opis prizora (»jedine pojave«) ne može mimoići i spomen srušenoga ljetnikovca, znaka vremena koje satire minulu ljepotu: »A kako su ispod tijeh visočina malašne i mirne kućice na Lapadskoj obali! Hlad ih je Petke već udunuo u ljubičastoj polutami, pak su počele saneno žmiriti, kao da su se umorile buljeći neprestano u tihu vodu što im noge pere i gdje sada regbi sve ištu da li je možebiti na dnu mutnoga zaljeva utonuo stari Gučetićev dvor - tajanstveni Lorko - koji je tu nedavno nestao sa svim svojim dobroćudnim duhovima i ponosnim lombardskim prozorima.« Ostavimo po strani što nikakvih lombardskih prozora nije bilo, poetični i lirski impregnirani zapis locira živu prostornu ranu nastalu nestankom značajnoga objekta, ukazuje na njegov središnji položaj, naglašen tobožnjim zapitkivanjem okolnih kuća o njegovoj tragičnoj sudbini. Isti taj Lorko ući će i u dijalošku dionicu teksta, u razmjenu misli između Gospođe Mare koja kaže: »Bit će zato što Gruž nije više... Gružlı, na što Gospar Niko (s muklim prezirnim smijehom) uzvraća: »Bacili su Lorka!»

Mnogo indikativniji je razgovor na samome kraju komada, kad se Gospar Lukša obraća svojem priprostom domaru, Konavljaninu Vuku (inače njegovu nezakonitom sinu, što ovaj ne zna): "Dunque! što bi ti učinio, Vuko, da ti ovu kuću dadu!«, na što Vuko spremno odvraća: »Eh! Da pravo kažem... Gosparu - prodo bih je!« Na taj je način definitivno izgubljena karika između vlasteoskih naraštaja i njihovih - makar pučkih, ali krvno bliskih - nasljednika. Po isteku životnog vijeka ostarjelih gospara njihova su dobra, $\mathrm{u}$ koja je uložena velika kulturna aktiva, i stvarno i simbolički postala - te do danas ostala - baština bez baštinika.

Vojnovićev sljedbenik u dramskoj elegičnoj evokaciji dubrovačke dekadanse, pisac Ernest Katić, situira u Pariz svoj komad »Vlastela u bjegstvu ili Antun Sorgo«, pozivajući se na zbiljsku parabolu života Antuna Sorkočevića. U jednom od dijaloga stara Kata govori o teškoćama vlastitoga izgnaničkog življenja, a sa sjetom spominje obiteljski ljetnikovac uz obale Omble: »Prošla sam zaista sve brige i zanoveti. Da nije druge nego samo pod starost doći u Prigj... Pa nije li naš palac u Rijeci mali raj...!«

I pisci izvan dubrovačke sredine znali su osjetiti duh dične starine i djelima navraćati u ambijente gospodarskoga ladanja ili u prostore sličnih kulturalnih svojstava. Petar Šegedin, zavičajan na bliskome otoku Korčuli, a radnim boravcima vezan i uz Orebić, posebno je umio dočarati atmosferu sredozemnoga krajolika, kuća i ljudi u njima i oko njih. Priča kao što je »Stare baštine« vezana je uz doživljaj prolaznosti, a »Priča o dva kamena«, znakovito posvećena upravo Cvitu Fiskoviću, situirana je u kuću pelješkog kapetana, oblikom i dostojanstvom sasvim nalik tradicionalnoj ladanjskoj izgradnji dubrovačkih gospara, samo dimenzijama i vremenom nastanka ponešto manjega dometa i značenja. Uostalom, opis mjesta, u kojemu prepoznajemo Orebiće, dovoljno govori o tipološkoj blizini s nekom dubrovačkom izvangradskom sredinom, recimo Rijeke dubrovačke: »Mjestance gdje je upravo pristajao brodić 'Šilo' bilo je nekako gospodskije od drugih naselja uz more. Odmah se to moglo vidjeti po veličini i izgledu zgrada, ali osobito vrtova, kojima su kuće bile okružene. Naročito stabalje njihovo - visoke palme i cedrovi, oleanderi i tamarisi, nešpule i žižule, a uz rub zidića, što su ograđivali vrtove, i bujne agave - isticalo je takav izgled naselja. Bilo sve to, zaista lijepo i izuzetno..." Ovaj Šegedinov pasus nam je dobro došao da konačno stavimo naglasak i na hortikulturni aspekt ladanjske arhitekture, koji se možda bolje i potpunije sačuvao izvan užega dubrovačkog područja i vlasteoskih zdanja, prepuštenih većoj nebrizi nakon gubljenja vlasničke pažnje.

Radiodramski tekst "Plavkovićev bal na vodi« Ivana Slamniga izvanredno je uspjeli hommage duhovnom supstratu ladanjskoga življenja. Žanrovski određen kao »slika iz starog Dubrovnika", motivski je inspiriran dugačkom pjesmom Oracija Mažibradića posvećenom Đivu Gunduliću, alias Plavkoviću, o kojoj smo s razlogom već govorili i obilno je navodili. Scena je određena samo jednom rečenicom: "Dvorište vile proširuje se na more, na splav. Svjetiljke.» Ali u Oracijevu obraćanju Plavkoviću dobivamo i sugestiju o autoru uređenja dvorca i proslave: »Dživo, krasno si sve uredio. Raskošno i ukusno. Znam da je sve rađeno po tvojim nacrtima."

Slamnigov temeljni interes bio je u ocrtavanju odnosa između agonista, dvojice pjesnika različitoga društvenog statusa i sreće u recepciji. Zadržavajući napetost pseudonimskog imenovanja, kao svojevrsne maske, naš suvremeni pisac pridaje Plavkoviću autorstvo djela kao što su »Orhan «, "Privojka« i »obove poruke« (aludirajući na Gundulićeva „Osmana«, »Dubravku« $\mathrm{i}$ »Davidove psalme«), a pritom se podrugljivo poigrava s njihovom utjecajnošću i značenjem. Sam Plavković nudi nova, drugačija kontekstualna određenja svojih pjesničkih radova, a prisustvujemo i izvedbi njegove pastorale »Potočna vila«, što se izvodi na taraci dvorca, a gosti su zamoljeni da zamisle ruralni krajolik. U finom ironičnom tonu, s malo sjete, Slamnig evocira siže kao borbu oko imanja i ljuveni zaplet, s time da naglašava lirsku žicu pučkoga pjesništva iracionalnih, simboličnih protega. Oracio pokušava slijediti taj ton i udvarati se vili, ali biva odbijen. U odužem monologu na kraju brani svoj program individualne slobode - nasuprot retorici Plavkovićeva primjera, a završni Plavkovićev osvrt jest svojevrsna pohvala različitosti. Po citatnosti i vještoj parafrazi, razradi zadanih motiva i zaigranoj kombinatorici elemenata, Ivan Slamnig je tim svojim djelom približio nam atmosferu du- 
brovačkog ladanja u postmodernoj perspektivi, omogućio uživanje u nesputanoj evokaciji literarne atmosfere i zadanih društvenih odnosa.

Sasvim drugačiji je pristup Nedjeljka Fabrija u drami „Čujete li svinje kako rokću u ljetnikovcu naših gospara?« Taj mirakul u jednom dijelu polemičan je od samoga naslova, koji eksplicitno konfrontira dva razdoblja: epohu izgradnje i slave življenja ("gosparsku«, »ljetnikovačku «) i fazu aktualnog poniženja (pretvaranja dvorca u svinjac). Rasprava koja se vodi uglavnom je usredištena oko mogućnosti obnove, korištenja ili prodaje vrijednoga zdanja u turističke svrhe, a okupljeni nasljednici razmatraju puteve i modalitete ostvarenja toga cilja, to jest da se riješe obaveze čuvanja i održavanja. Stara Nuncula, međutim, kao da predstavlja genius loci i upozorava na etos ambijenta. $U$ povremenom intertekstualnom dijalogu s Vojnovićevim primjerom Fabrio pojačava literarnu slojevitost svojega pristupa, no zavičajnu komponentu podiže za jedan stupanj, pretvarajući je u domovinsku sudbinu.

U monumentalnim romanesknim ostvarenjima Luka Paljetka, usredištenima oko biografskih okolnosti egzemplarnih zbiljskih likova Cvijete Zuzorić i Marina Držića, dana je zapravo vrlo široka freska dubrovačkog društvenog i kulturnog života 16. stoljeća. Faktografijom podložena, a fantazijom oživljena i razigrana scenerija obuhvaća mnoge europske lokalitete, posebno one na Apeninskom poluotoku, ali nužno prati i kretanja protagonista i suputnika također i po samom području Republike. Ladanje i ljetnikovci stoga su također povremenim pozornicima susreta i razgovora. Posebno se to odnosi na Trsteno, gdje slijedeći poticaje Gučetićevih teorijskih tekstova, a pogotovo njihovih predgovora, Paljetak smješta važne epizode Cvijetina življenja i djelovanja. Svojom golemom erudicijom i ništa manjim ulogom pjesničke rekonstrukcije prostora i duhovnog ambijenta, naš suvremeni autor nudi kompleksnu viziju renesansne poetike i prakse, gotovo kao legitimni nasljednik velikih uzora i literarnih modela kojima se bavi. Čitanje "Skrovitog vrta" (indikativnog već naslovom za tematiku ladanja) $i$ »Marina» nudi nam povlašteni prečac za razumijevanje elitne kulture staroga Dubrovnika, te njezine povezanosti s ambijentom.

Književnost nije mogla ne reagirati i na zasad posljednji čin degradacije i razaranja dubrovačkih ljetnikovaca. U pripovjednoj knjizi »Ujedinjenje ili smrt«, podnaslovljenoj "prizori iz dubrovačke dramske sudbine « Čedo Prica je literarno interpretirao napad Jugoarmije na dubrovačku okolicu, a središnji lik njegove naracije je upravo penzionirani general te iste vojske, potomak stare dubrovačke vlasteoske obitelji De Kverča, koji se po umirovljenju povukao u svoj ljetnikovac da bi tamo proživio zadnje dane. Grotesknost i paradoksalnost početne situacije dobrodošla je za ukazivanje na apsurd povijesnih prilika, u kojima se, gotovo nakon dva stoljeća ponavlja epizoda pohare iz napoleonskih ratova, a kultura i uljuđenost bivaju pogaženi i povrijeđeni.

Penzionirani general Dživo vjerovao je da će povlačenjem u zabit Male Luke, nasuprot Lopudu i Koločepu, i u tišini naslijeđenog i, njegovim naporima, obnovljenog ljetnikovca uživati mir, ali njegovi bivši kolege to mu ne samo onemogućuju, nego ga i ubijaju pogodivši ga na taraci omiljenoga mu zdanja, zajedno sa suprugom Anamarijom. To recentno poglavlje sudbinske povezanosti dubrovačke vlastele - i dubrovačke sredine, općenito - $s$ ambijentom ladanja i prostorima uljuđene prirode završava naglo i okrutno. Nakon intenzivnog razdoblja raskoši i sjaja i nakon višestoljetnog dotrajavanja i postupnog pada u sjenu i suton, u posljednjem činu literarne evokacije dubrovačkih ljetnikovaca imamo i amblematičnu žrtvu, koja kao da traži katarzu i iskupljenje. 